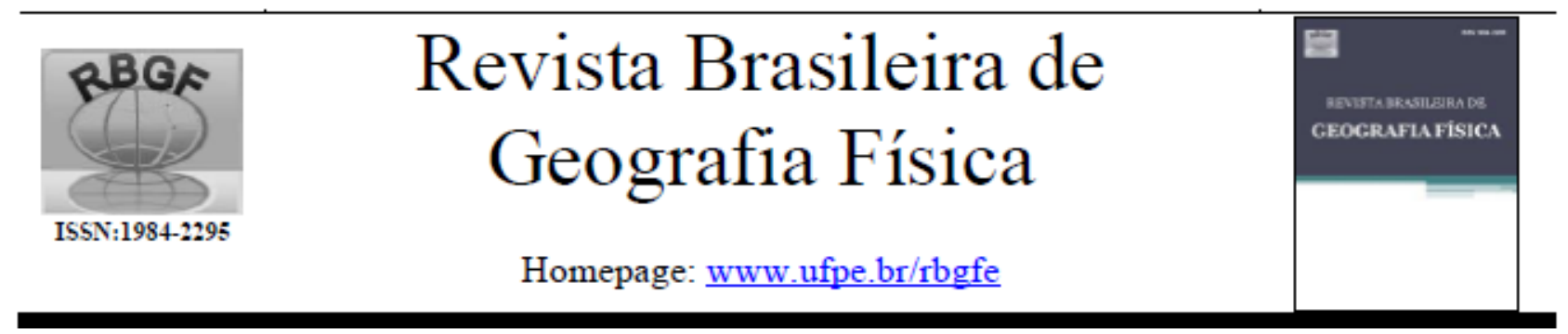

\title{
Comportamento climático do balanço do vento térmico na América do Sul de acordo com os eventos ENOS: Estudo preliminar
}

\author{
Mônica Vaz Lima'; André Becker Nunes²
}

${ }^{1}$ Graduanda em Geografia na UFPEL, Autor correspondente: e-mail: lima.monicav@gmail.com. Endereço: Rua Félix da Cunha, 520. Curso de Geografia, Pelotas-RS, 96010-901; ${ }^{2}$ Professor do Departamento de Meteorologia, UFPEL, andre.nunes@ufpel.edu.br, Campus Capão do Leão, Faculdade de Meteorologia, Pelotas-RS.

Artigo submetido em 23/07/2017 e aceite em 20/05/2018.

\section{R E S U M O}

O balanço do vento térmico indica a relação entre o gradiente meridional de temperatura e o cisalhamento vertical do vento, o que explica a existência do jato de altos níveis - chamado de corrente de jato, ou simplesmente jato - em latitudes médias e altas. É esperado que a posição do jato corresponda a condições de instabilidade em superfície. O fenômeno climático ENOS (El Niño-Oscilação Sul) provoca uma alteração no gradiente de temperatura em baixos níveis, pois muda o padrão normal de temperatura da superfície do mar do Pacífico Tropical leste. Assim, o presente trabalho usa dados de reanálise II do NCEP (1981-2010) para analisar como que as três diferentes fases do ENOS (El Niño, La Niña e neutra) modificam o padrão médio climatológico de balanço do vento térmico no continente sulamericano. Primeiramente, os resultados mostraram boa associação entre os núcleos do jato e as regiões de maior gradiente de temperatura em 850 hPa. Nos períodos de La Niña, o jato apresentou-se mais intenso no inverno sobre o continente. Já em anos de El Niño observou-se jato mais intenso em latitudes médias sobre o Pacífico, na costa oeste do continente, principalmente no verão e primavera, indicando que o incremento de temperatura na superfície do mar no Pacífico acarreta em maior gradiente de temperatura em latitudes médias e, consequentemente, em uma corrente de jato mais intensa.

Palavras-chave: Corrente de jato, gradiente meridional de temperatura, El Niño, La Niña

\section{Climatic behavior of thermal wind balance in South America according to ENSO events: Preliminary study}

\section{A B S T R A C T}

The thermal wind balance shows the relation between meridional gradient of temperature and vertical wind shear, explaining the existence of the upper-tropospheric jet - called jet stream, or simply jet - in high and mid-latitudes. It is expected that jet position is associated to instability conditions in surface. The climate phenomenon ENSO (El Niño-South Oscillation) causes a perturbation in the low levels temperature gradient, since that changes the normal pattern of sea surface temperature of eastern tropical Pacific ocean. Thus, this work employs NCEP II reanalyses dataset (1981-2010) to analyze how the three phases of ENSO (El Niño, La Niña and neutral) modify the climatic pattern of thermal wind balance in the South American continent. First, the results showed good association between jet streaks and the regions with highest temperature gradient at $850 \mathrm{hPa}$. During La Niña periods the jet stream had become more intense in the winter, over the continent. On the other hand, during El Niño, a more intense jet was observed in the mid-latitudes over Pacific, on the west coast of the continent, mainly in summer and spring, indicating that the increase in sea surface temperature in Pacific entails a higher mid-latitudes temperature gradient and, therefore, a more intense jet stream.

Keywords: jet stream, meridional gradient of temperature, El Niño, La Niña 


\section{Introdução}

$\mathrm{O}$ aquecimento diferencial da superfície do globo no sentido norte-sul devido à radiação solar incidente provoca um natural gradiente meridional de temperatura, com valores superficiais aumentando em direção aos trópicos e diminuindo em direção aos polos. Com a rotação da Terra surgem as grandes células de circulação meridional, com o gradiente de temperatura ficando mais intenso entre elas.

$\mathrm{O}$ balanço do vento térmico indica que a simples existência deste gradiente de temperatura em baixos níveis acarreta em cisalhamento vertical do vento, culminando com a existência da Corrente de Jato (ou simplesmente jato) próxima à tropopausa, entre as células da circulação média meridional (Bluestein, 1992).

Advecções de temperatura em grande escala, provocadas pelo movimento de massas de ar associado à sistemas frontais, tendem a manter o gradiente meridional de temperatura constante sob ponto de vista climatológico à medida que provoca a troca de ar frio dos polos pelo ar quente dos trópicos. Contudo, localmente, na zona estreita onde as massas se encontram - a zona frontal - o gradiente aumenta, provocando aumento do cisalhamento vertical do vento, o que caracteriza as instabilidades baroclínicas (Holton, 2004).

Por si só, a corrente de jato é um indicativo de possibilidade de instabilidade em superfície; adicionalmente, tem-se muita atenção ao seu formato, dado que ondulações do sistema representam cavados e cristas que, conforme a teoria quase-geostrófica, advectam vorticidade implicando em movimentos verticais e alterações no campo de altura geopotencial em superfície (Keyser e Shapiro, 1986). Ou seja, sistemas baroclínicos, normalmente transientes, estão associados à ondulações na corrente de jato, diminuindo seu comprimento de onda e, não raro, acarretando na formação de vórtices ciclônicos de altos níveis extratropicais (Palmén e Nagler, 1949; Bluestein e Speheger, 1995; Nunes, 2017). Por outro lado, padrões climatológicos da corrente de jato apresentam ondulações devido à fatores de escala temporal maior, como oscilações climáticas ou aquecimento diferencial zonal devido à continentalidade.

Dentre as oscilações climáticas mais estudadas na literatura especializada, o ENOS (El Niño - Oscilação Sul) é a que mais influencia no clima da América do Sul, especialmente quanto ao regime de precipitação (Rao e Hada, 1990; Grimm et al., 2000; Barros et al., 2002; Rao et al., 2002;
Grimm, 2003, Freire et al., 2011; Chechi e Sanches, 2013; Santos et al., 2013; Sousa et al., 2015; Grimm e Aceituno, 2015; Rodrigues et al., 2017, Salazar-Gáscon e Ferreira, 2018, entre outros) ou mesmo quanto aos eventos extremos de precipitação (Grimm e Tedeschi, 2009, entre outros). Basicamente, tem-se que durante o $\mathrm{El}$ Niño (La Niña) ocorrem anomalias positivas (negativas) de precipitação na primavera e no outono-inverno do ano seguinte no sul do Brasil (Grimm, 2003; 2004; Grimm et al., 1998) e abaixo (acima) do normal no norte da América do Sul (Marengo, 1992; Coelho et al., 2002; Grimm, 2003; 2004).

Eventos de El Niño (EN) Canônico - EN Modoki (Ashok et al., 2007; Tedeschi et al., 2013), não será considerado aqui - são caracterizados pelo aquecimento anômalo da superfície do mar no Pacífico tropical leste. Este aquecimento tende a aumentar o gradiente meridional de temperatura que, por sua vez, acarreta em uma corrente de jato mais intensa e zonal. Esta intensificação da corrente de jato (no caso, corrente de jato subtropical) em anos de EN é encontrada na literatura, como por exemplo em Satyamurty et al. (1998), Tedeschi et al. (2013) e Pereira et al. (2017). Sob tais condições, a corrente de jato atua de dois modos: ou como bloqueio, concentrando os sistemas frontais na região sul do Brasil; ou como forçante dinâmica de complexos convectivos de mesoescala na região do Chaco (Velasco e Fritsch, 1987) devido à advecção de vorticidade. Estes sistemas convectivos deslocam-se para leste (Grimm et al., 1998 e 2000; Grimm e Tedeschi, 2009), frequentemente atingindo a região Sul do Brasil. Rutllant e Fuenzalida (1991), por exemplo, mostram maior frequência de bloqueios atmosféricos em anos de EN. Tais características explicam, parcialmente, as anomalias positivas de precipitação na região sul do Brasil em anos de EN. Por outro lado, a fase fria do ENOS, o La Niña (LN), quando o gradiente meridional de temperatura tende a diminuir devido ao resfriamento da superfície do mar do Pacífico tropical central e leste, está associado com precipitação abaixo do normal na região sul do Brasil (Grimm et al., 2000).

A relação entre aumento do gradiente meridional de temperatura e o aumento do cisalhamento vertical do vento é facilmente observada pelas equações do balanço do vento térmico abaixo, compostas a partir do vento geostrófico e da equação da hidrostática (Bluestein, 1992): 


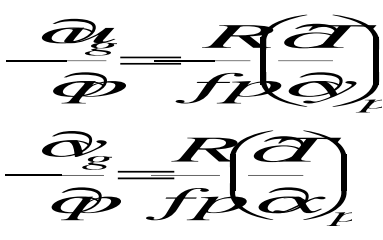

Onde $u_{g}$ e $v_{g}$ são as componentes zonal e meridional do vento geostrófico, respectivamente, $p$ é a pressão atmosférica, $R$ é a constante dos gases para o ar seco, $f$ é a aceleração de Coriolis, $T$ é a temperatura do ar, $x$ e $y$ são as direções zonal e meridional, respectivamente. Considerando somente a componente zonal (Eq. 1), que em altos níveis tem magnitude muito superior a componente meridional, temos que para o Hemisfério Sul o vento aumenta de intensidade com a altura proporcionalmente ao gradiente meridional de temperatura. Ou seja, quanto maior o gradiente, maior a intensidade do jato.

O objetivo deste trabalho é a análise preliminar do balanço do vento térmico sobre a América do Sul para as diferentes fases do fenômeno ENOS: EN, LN, e anos neutros. A análise consistirá da observação, por meio de dados de reanálise, do gradiente de temperatura em baixos níveis e da corrente de jato. Posteriormente, é verificado o comportamento dos casos de ENOS mais intensos.

\section{Material e métodos}

Neste trabalho foram usados dados em pontos de grade de temperatura do ar e velocidade do vento da Reanálise 2 do NCEP (National Centers for Environmental Prediction) com resolução horizontal de $2.5^{\circ}$ e 17 níveis verticais (Kanamitsu et al., 2002). Foram usados 30 anos de dados, de 1981 a 2010.

O balanço do vento térmico foi verificado a partir da relação entre os campos de gradiente meridional de temperatura em baixos níveis e a magnitude do vento em $250 \mathrm{hPa}$. Para se verificar qual nível mais significativo de gradiente meridional de temperatura, foi comparado o valor do coeficiente de correlação espacial desta variável em $1000 \mathrm{hPa}$ e $850 \mathrm{hPa}$ com a magnitude do vento em $250 \mathrm{hPa}$.

$O$ fenômeno ENOS foi verificado de acordo com o índice ONI (Oceanic Niño Index), obtidos do Climate Prediction Center (CPC) do National Oceanic and Atmospheric Administration (NOAA), que é baseado na média móvel de três meses corridos da anomalia de temperatura da superfície do mar (TSM) na região do Niño $3.4\left(5^{\circ} \mathrm{S}-5^{\circ} \mathrm{N} ; 120^{\circ} \mathrm{W}-170^{\circ} \mathrm{W}\right)$. Considera-se uma média trimestral de EN (LN) quando apresentar por pelo menos cinco meses consecutivos anomalias de TSM de $+0.5^{\circ} \mathrm{C}$ ($0.5^{\circ} \mathrm{C}$ ) com relação à média climatológica de 30 anos, atualizada a cada 5 anos. Os dados do índice ONI são obtidos do site: (http://www.cpc.ncep.noaa.gov/products/analysis monitoring/ensostuff/ensoyears.shtml). Aqui, para a análise das médias dos eventos não foi considerada a intensidade do fenômeno, apenas a fase. Já a análise posterior considerou os casos mais intensos de EN e LN, para comparação com os resultados médios dos eventos.

A análise sazonal deste trabalho considerou como verão os meses de Dezembro, Janeiro e Fevereiro (DJF), outono sendo Março, Abril e Maio (MAM), inverno sendo Junho, Julho e Agosto (JJA) e primavera sendo Setembro, Outubro e Novembro (SON).

\section{Resultados e discussão}

Como já mencionado, a literatura indica a relação entre o jato e o gradiente meridional de temperatura em baixos níveis. Desta forma, resta saber a qual nível de pressão deve-se considerar "baixo nível", se em $1000 \mathrm{hPa}$, próximo a superfície, ou em $850 \mathrm{hPa}$, onde o gradiente de temperatura é mais influenciado pela presença das massas de ar.

A tabela 1 mostra a análise sazonal do cálculo do coeficiente de correlação espacial entre o gradiente meridional de temperatura em 1000 hPa e em $850 \mathrm{hPa}$ e a magnitude do vento em 250 hPa, usando dados mensais de 1981 a 2010. Como o objetivo é de se verificar a relação do gradiente de temperatura e a corrente de jato, calculou-se o coeficiente para o domínio de $15^{\circ} \mathrm{S}-60^{\circ} \mathrm{S}$ e usouse dos dados de vento somente os valores acima de $24 \mathrm{~m} \mathrm{~s}^{-1}$.

Tabela 1. Correlação espacial média para cada estação do ano entre o gradiente meridional de temperatura, considerando dois níveis $(850 \mathrm{hPa}$ e $1000 \mathrm{hPa}$ ) e a magnitude do vento (valores acima de $24 \mathrm{~m} \mathrm{~s}^{-1}$ ) em $250 \mathrm{hPa}$.

\begin{tabular}{ccccc} 
& $D J F$ & $M A M$ & $J J A$ & SON \\
\hline $850 \mathrm{hPa}$ & 0.89 & 0.87 & 0.46 & 0.73 \\
\hline $1000 \mathrm{hPa}$ & 0.74 & 0.76 & 0.24 & 0.48 \\
\hline
\end{tabular}

Como em Yang e Delsole (2012), consideremos aqui correlações robustas aquelas com coeficientes maiores que 0.75 , correlação moderada as com valores entre 0.75 e 0.5 , e as fracas com valores abaixo de 0.5 . Observa-se para o verão (DJF) e outono (MAM) boa relação entre o gradiente meridional de temperatura e o núcleo do jato. Nota-se mais associação do gradiente em 
$850 \mathrm{hPa}$ do que em $1000 \mathrm{hPa}$. Explicações para isto residem no fato de que em $850 \mathrm{hPa}$ ocorre o maior transporte de massas de ar, o que intensifica os gradientes, enquanto que em $1000 \mathrm{hPa}$ ainda existe muita influência da superfície. Além disso, em $850 \mathrm{hPa}$, por ser mais elevado que em 1000 $\mathrm{hPa}$, a defasagem ao jato é um pouco menor apesar que para níveis superiores a $850 \mathrm{hPa}$, a correlação (não mostrada aqui) é menor. Ou seja, o gradiente meridional de temperatura analisado aqui será o observado no nível de $850 \mathrm{hPa}$.

A análise sazonal mostra que para ambos níveis, apenas o inverno (JJA) apresenta correlação fraca entre o gradiente de temperatura e o núcleo do jato. Tal comportamento se repete na primavera (SON) para $1000 \mathrm{hPa}$, sendo moderada para o nível de $850 \mathrm{hPa}$. As explicações para isto podem ser mais facilmente entendidas com a ajuda das figuras a seguir. A Figura 1 mostra os campos de magnitude do vento acima de $24 \mathrm{~m} \mathrm{~s}^{-1}$ em $250 \mathrm{hPa}$ (corrente de jato) e

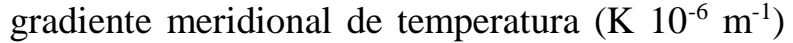
em $850 \mathrm{hPa}$ para o verão (DJF). São mostrados: o campo climatológico (1981-2010), as médias para os episódios de EN, para os episódios de LN e para os episódios neutros.

As Figuras 3, 5 e 7 apresentam o mesmo, mas para o outono (MAM), inverno (JJA) e primavera (SON) respectivamente, enquanto que as figuras 2, 4, 6 e 8 mostram as respectivas anomalias provocadas pelas fases do ENOS. Aqui, são consideradas anomalias a simples diferença entre os padrões médios de ENOS e a média climatológica. Para melhor visualização da região de interesse, foram desconsiderados valores pequenos ou negativos do gradiente de temperatura, sendo o gradiente negativo indicador de temperatura aumentando para o sul (pontos raros na zona extratropical).

Observa-se, visualmente, boa relação entre as variáveis para o verão, conforme indica a tabela 1. Valores significativos das duas variáveis são encontrados somente em latitudes médias, devido às suas características baroclínicas. Nos quatro casos notam-se dois núcleos com valores maiores de gradiente de temperatura: sobre o continente (Argentina) e no oceano Atlântico. A corrente de jato, observada pelos contornos de magnitude de velocidade do vento, também apresenta um padrão similar. Contudo, nota-se o contorno de $27 \mathrm{~m} \mathrm{~s}^{-1}$ mais ao norte, próximo do sul do Brasil, nos casos de EN.

A Figura 2 mostra a diferença entre as fases do ENOS e a média climatológica para o período de 1981-2010 para DJF. Focou-se na região extratropical, onde se encontram as anomalias de interesse de acordo com a Figura 1.
Nota-se, como esperado, anomalias positivas (negativas) de magnitude da corrente de jato associadas com anomalias positivas (negativas) de gradiente meridional de temperatura. Observa-se valores menores nos anos neutros (Fig. 2C), indicando maior semelhança destes períodos com a média climatológica. Este também é um resultado esperado, haja vista que dos 360 meses em estudo, $181(50,3 \%)$ são neutros, $100(27,8$ \%) são EN e $79(21,9$ \%) são LN.

Os campos de EN (Fig. 2A) e LN (2B), no geral, são opostos: observam-se anomalias positivas (negativas) tanto de vento quanto de gradiente de temperatura em latitudes menores $\left(20^{\circ}\right.$ à $35^{\circ} \mathrm{S}$, aproximadamente), exceto sobre o continente, nos casos de EN (LN). Ou seja, no verão em anos de EN tem-se um jato mais intenso nesta faixa latitudinal, exceto pela região sobre o sul do Brasil. Uma hipótese para esta anomalia negativa localizada é a existência de uma crista em altos níveis ao norte da corrente de jato, associada ao calor da camada atmosférica continental desta época do ano, potencializado pelo EN.

A Figura 3 mostra o mesmo que a Figura 1, mas para o outono (MAM). Em todos os casos, observam-se sobre o continente três centros isolados de gradiente de temperatura: o mais intenso em aproximadamente $37^{\circ} \mathrm{S}-70^{\circ} \mathrm{W}$ (sotavento dos Andes), outro intenso sobre o Uruguai e um mais fraco no noroeste da Argentina, também à sotavento dos Andes. Sabese que a forçante orográfica provoca instabilidade em superfície devido ao escoamento subsidente montanha abaixo, e esta instabilidade pode, com o tempo, aumentar o gradiente de temperatura em superfície. No caso do centro no noroeste argentino, pode estar relacionado com a Baixa do Noroeste Argentino (BNOA) (Seluchi et al., 2003). Já no caso do centro sobre o sul do Brasil, pode estar relacionado com o aumento, em comparação com o verão (Fig. 1) da frequência dos sistemas frontais. Novamente, a isolinha de 27 $\mathrm{m} \mathrm{s}^{-1}$ serve como referencial comparativo para se analisar o jato, onde podemos observar no caso do EN (Fig. 3B) o jato mais intenso no Atlântico, ao contrário do LN (Fig. 3C), em que o jato está mais intenso no Pacífico.

$\mathrm{Na}$ Figura 4, para o outono (MAM), também observa-se a relação direta entre a variação da magnitude do vento e a variação do gradiente meridional de temperatura em $850 \mathrm{hPa}$, assim como, no geral, um comportamento oposto entre EN (Fig. 4A) e LN (Fig. 4B), com valores positivos (negativos) no Pacífico subtropical e Atlântico extratropical nos casos de EN (LN). A Fig. 4C mostra que em anos sem influência de EN 
ou LN, ocorre um enfraquecimento do vento nos subtrópicos $\left(20^{\circ}\right.$ à $\left.30^{\circ} \mathrm{S}\right)$ e intensificação nos extratrópicos $\left(30^{\circ}\right.$ à $\left.45^{\circ} \mathrm{S}\right)$.

A Figura 5 mostra o mesmo que a Fig. 1, mas para o inverno (JJA). Como esperado, observa-se tanto jato quanto o gradiente de temperatura mais ao norte do que nas outras estações. Isto se deve ao deslocamento mais frequente e intenso de massas de ar polares em direção às baixas latitudes nesta estação. Em todos os casos, nota-se um centro isolado de intenso gradiente de temperatura próximo à costa oeste do continente, na faixa de aproximadamente $17^{\circ} \mathrm{S}$. Este centro localiza-se próximo do eixo do cavado em altos níveis, como indicado pelo formato do jato. É normal a ocorrência de tal cavado, ou até mesmo um vórtice ciclônico de altos níveis, nesta região (Garreaud e Fuenzalida, 2007) muitas vezes associado com o jato nesta estação (Fuenzalida et al., 2005).

Na Figura 6 observa-se, novamente, que as anomalias encontradas nos casos de EN (Fig. 6A) são opostas aos casos de LN (Fig. 6B). Notase nos casos de EN que em JJA as regiões de anomalia positiva de gradiente de temperatura concordam com as regiões ciclogenéticas do Atlântico Sul, apontadas em Gan e Rao (1991) e Reboita et al. (2010), o que faz sentido dado que a ciclogênese extratropical é um sistema baroclínico. Os meses de $\mathrm{LN}$ apresentam no inverno valores intensos e positivos de anomalia de vento e gradiente de temperatura. Haja vista que a literatura (Grimm et al., 1998, por exemplo) indica precipitação abaixo da média em anos de LN para esta região, tal aumento do gradiente não implica na formação de sistemas precipitantes pois não se deve ao escoamento quente e úmido de norte, e sim ao anômalo escoamento em baixos níveis de sul, conforme mostrado em Barros et al. (2002). Tal escoamento transporta ar frio para regiões tipicamente mais quentes, e a diminuição da precipitação neste período em anos de $\mathrm{LN}$ intensifica o gradiente na região, pois permite maior insolação direta. Tal anomalia positiva sobre esta região também é observada nas outras estações, mas com menor intensidade.

Na primavera, observa-se o jato ainda em latitudes mais baixas se comparado com verão e outono. Nota-se o jato mais intenso, e uma área maior de forte gradiente de temperatura, nos anos de EN (Fig. 7B), com núcleo de $33 \mathrm{~m} \mathrm{~s}^{-1}$ sobre Uruguai, Argentina e Rio Grande do Sul. Assim como no inverno, nota-se valores de gradiente consideráveis (mais intensos em anos neutros, Fig. 7C) associados ao cavado extratropical em altos níveis à oeste dos Andes.

O comportamento oposto entre EN (Fig. 8A) e LN (Fig. 8B) também é notado nos campos de anomalia de vento e gradiente de temperatura nesta estação. Nos anos de EN, nota-se jato e gradientes mais intensos no Pacífico Subtropical, sobre o continente e em boa parte do Atlântico. Quanto aos anos de LN, observam-se valores consideráveis de aumento de gradiente e de vento sobre o sul do Brasil. Nota-se boa concordância espacial entre as anomalias dos anos neutros (Fig. 8C) e dos anos de LN, com os anos neutros apresentando anomalias ainda maiores, especialmente no sudeste do continente.

Uma forma de se analisar a variação sazonal da intensidade do jato é verificando o comportamento do núcleo, que podemos definir por um certo limiar, no caso, $30 \mathrm{~m} \mathrm{~s}^{-1}$. No verão (Fig. 1) o núcleo se encontra sobre o Atlântico extratropical e um pouco menor no Pacífico extratropical. Comportamento um pouco diferente é verificado nos meses de $\mathrm{EN}$, quando não se observa o núcleo sobre o Pacífico, mas se observa o núcleo do Atlântico um pouco maior que nas outras fases. No outono (Fig. 3), o núcleo que estava no Pacífico não é mais encontrado, e o do Atlântico não é mais observado nos casos de LN. Já no inverno (Fig. 5), o jato atinge seu auge de intensidade, e podemos definir o núcleo pelo valor de $33 \mathrm{~m} \mathrm{~s}^{-1}$, que se encontra no Pacífico e Atlântico extratropicais, exceto no caso de $\mathrm{LN}$, em que este valor é encontrado em boa parte do continente (norte da Argentina e sul do Brasil) além dos oceanos adjacentes, especialmente o Atlântico. Ou seja, em anos de LN, o jato fica mais intenso nestes locais durante o inverno, o que pode ser verificado no campo de anomalia (Fig. 6B). Na primavera (Fig. 7), o núcleo de $30 \mathrm{~m}$ $\mathrm{s}^{-1}$ nos eventos de $\mathrm{EN}$ compreende uma área bem maior que das outras fases, indicando um jato bem mais intenso, como pode ser verificado na Figura $8 \mathrm{~A}$. 

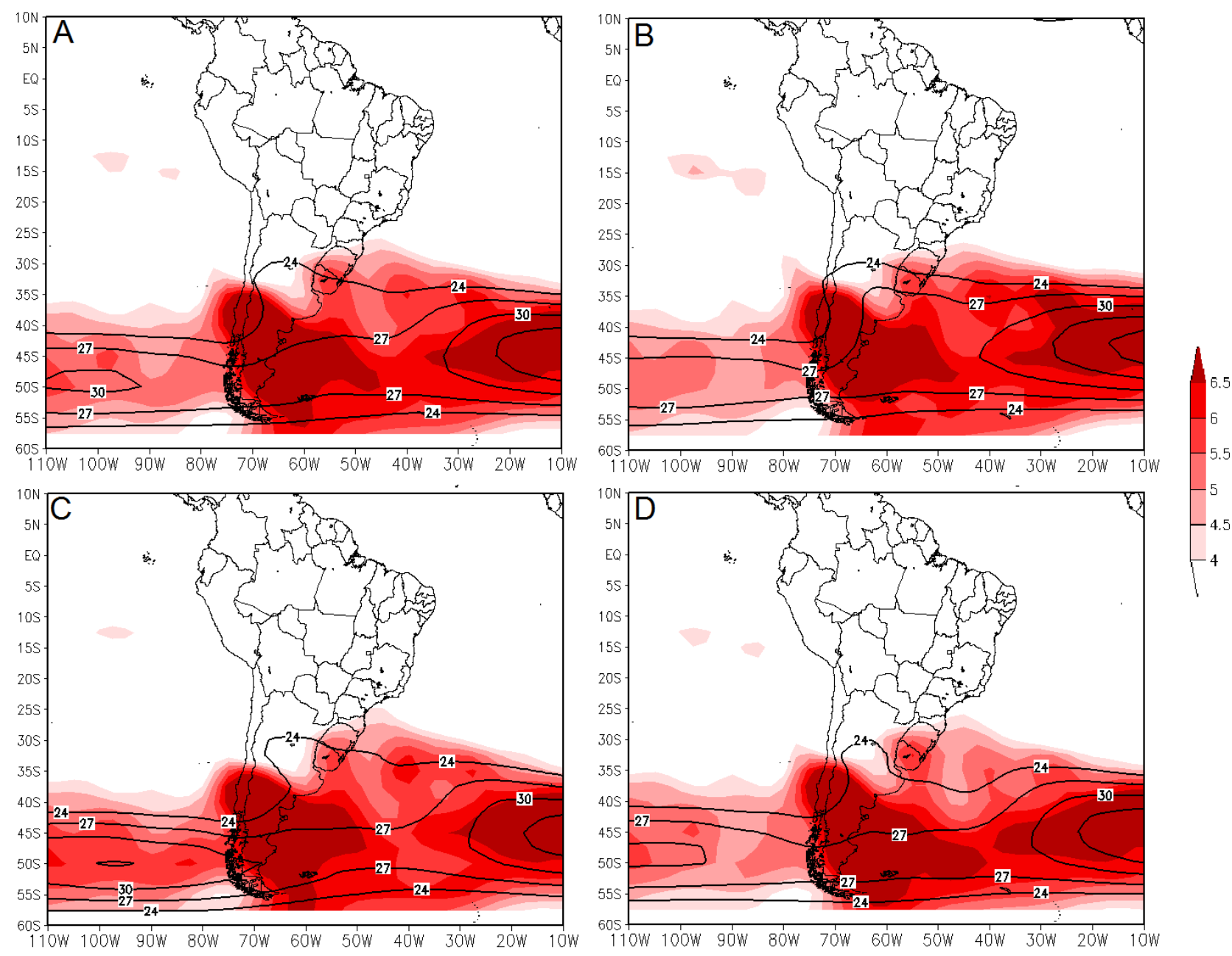

Figura 1. Campo de magnitude do vento $\left(\mathrm{m} \mathrm{s}^{-1}\right)$ em $250 \mathrm{hPa}$ para valores acima de $24 \mathrm{~m} \mathrm{~s}^{-1}$ (contorno) e gradiente meridional de temperatura $\left(\mathrm{K}_{10}^{-6} \mathrm{~m}^{-1}\right)$ em $850 \mathrm{hPa}$ para valores acima de $6 \mathrm{~K}^{-6} 0^{-6} \mathrm{~m}^{-1}$ (sombreado), para o verão (DJF) onde (A) é a média climatológica, (B) é a média dos meses com EN, (C) a média dos meses com LN e (D) a média dos meses neutros. 


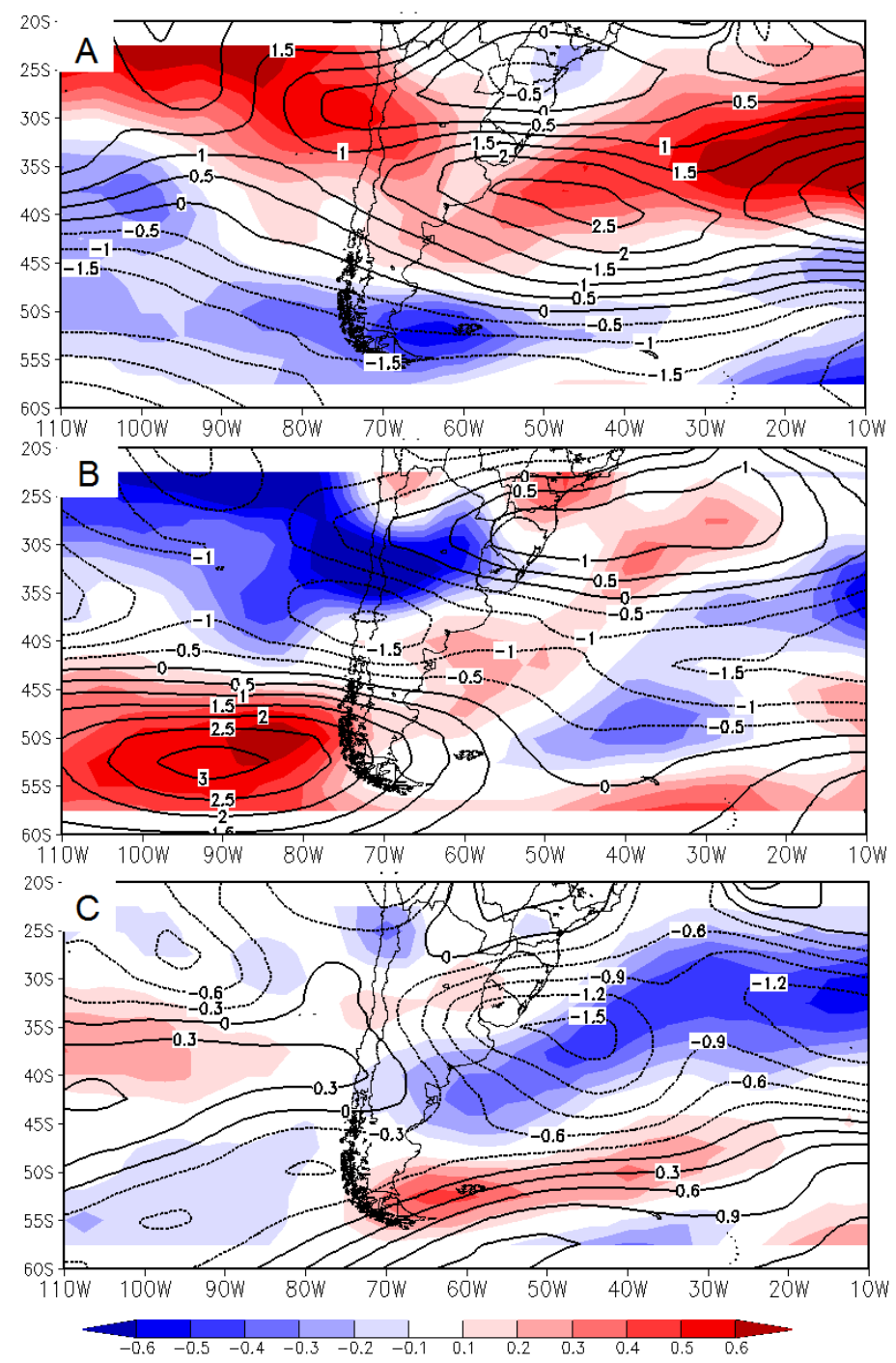

Figura 2. Anomalias (diferença entre o evento e a média climatológica) de magnitude do vento ( $\mathrm{m} \mathrm{s}^{-1}$ ) em

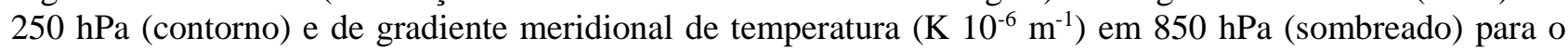
verão (DJF) onde (A) é a média dos meses com EN, (B) é a média dos meses com LN e (C) a média dos meses neutros. 

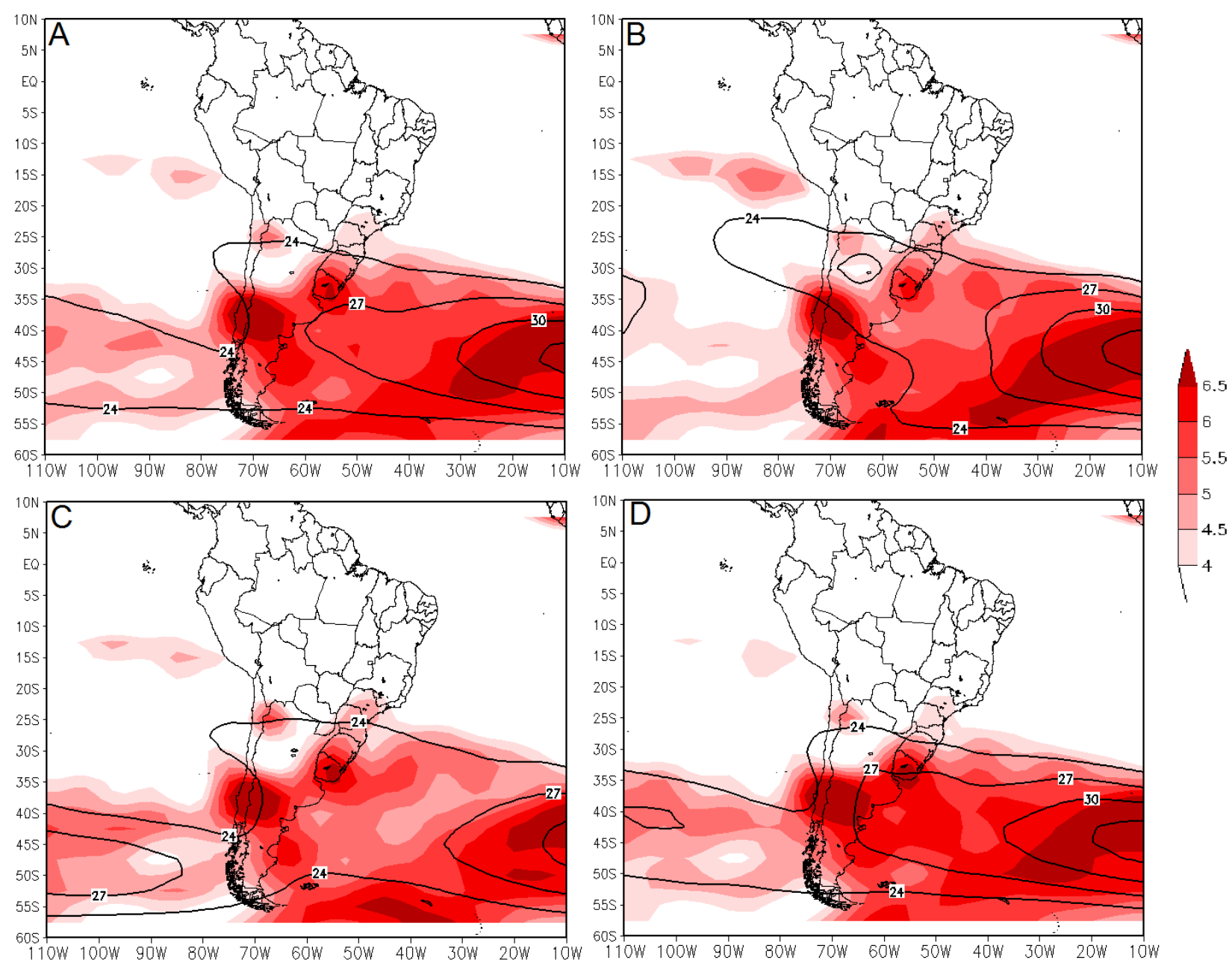

Figura 3. Campo de magnitude do vento $\left(\mathrm{m} \mathrm{s}^{-1}\right)$ em $250 \mathrm{hPa}$ para valores acima de $24 \mathrm{~m} \mathrm{~s}^{-1}$ (contorno) e

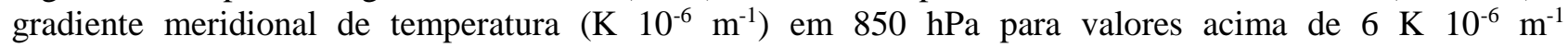
(sombreado), para o outono (MAM) onde (A) é a média climatológica, (B) é a média dos meses com EN, (C) a média dos meses com LN e (D) a média dos meses neutros. 

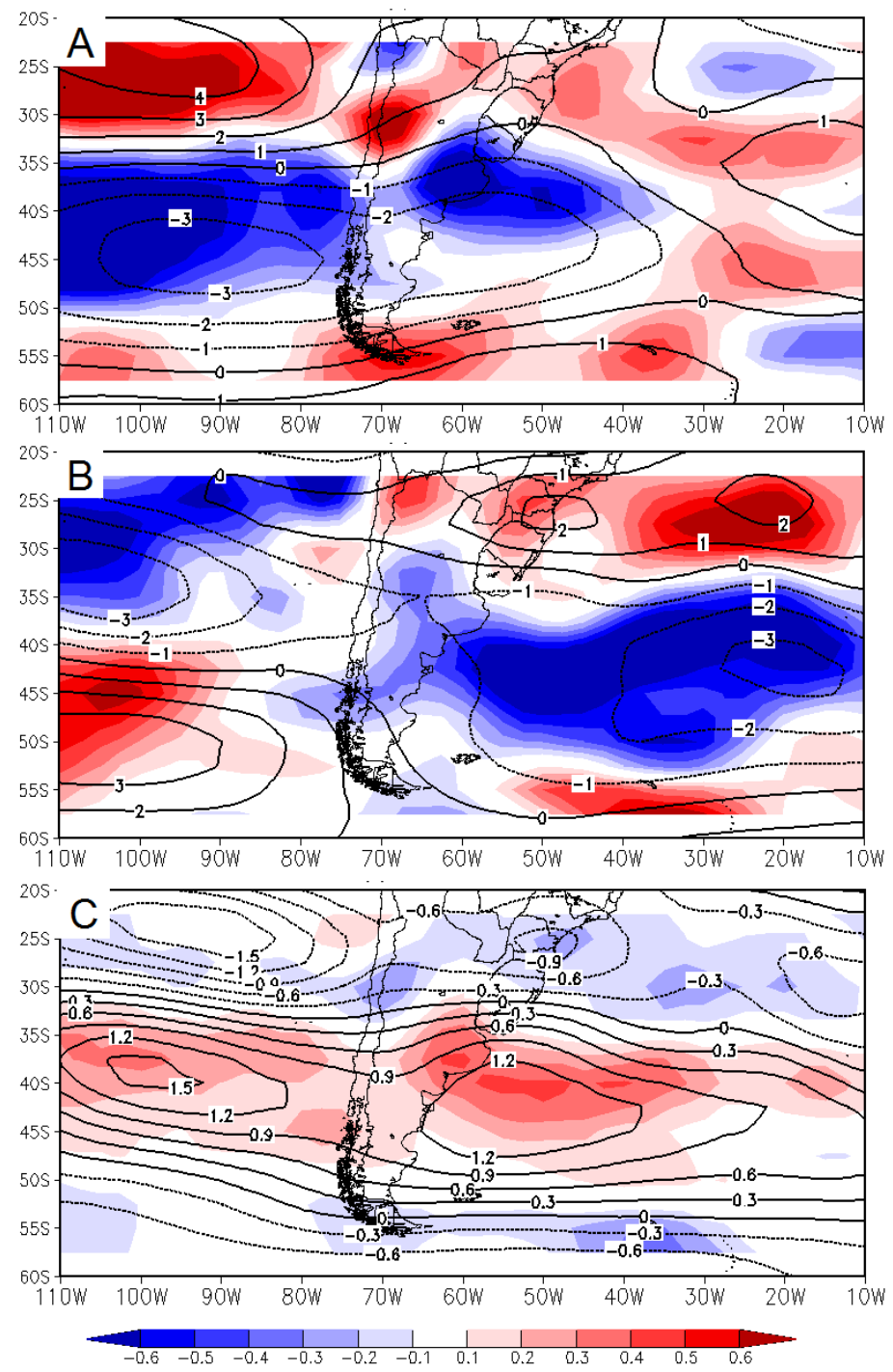

Figura 4. Anomalias (diferença entre o evento e a média climatológica) de magnitude do vento ( $\mathrm{m} \mathrm{s}^{-1}$ ) em

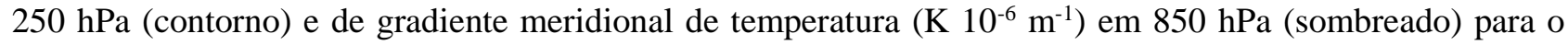
outono (MAM) onde (A) é a média dos meses com EN, (B) é a média dos meses com LN e (C) a média dos meses neutros. 

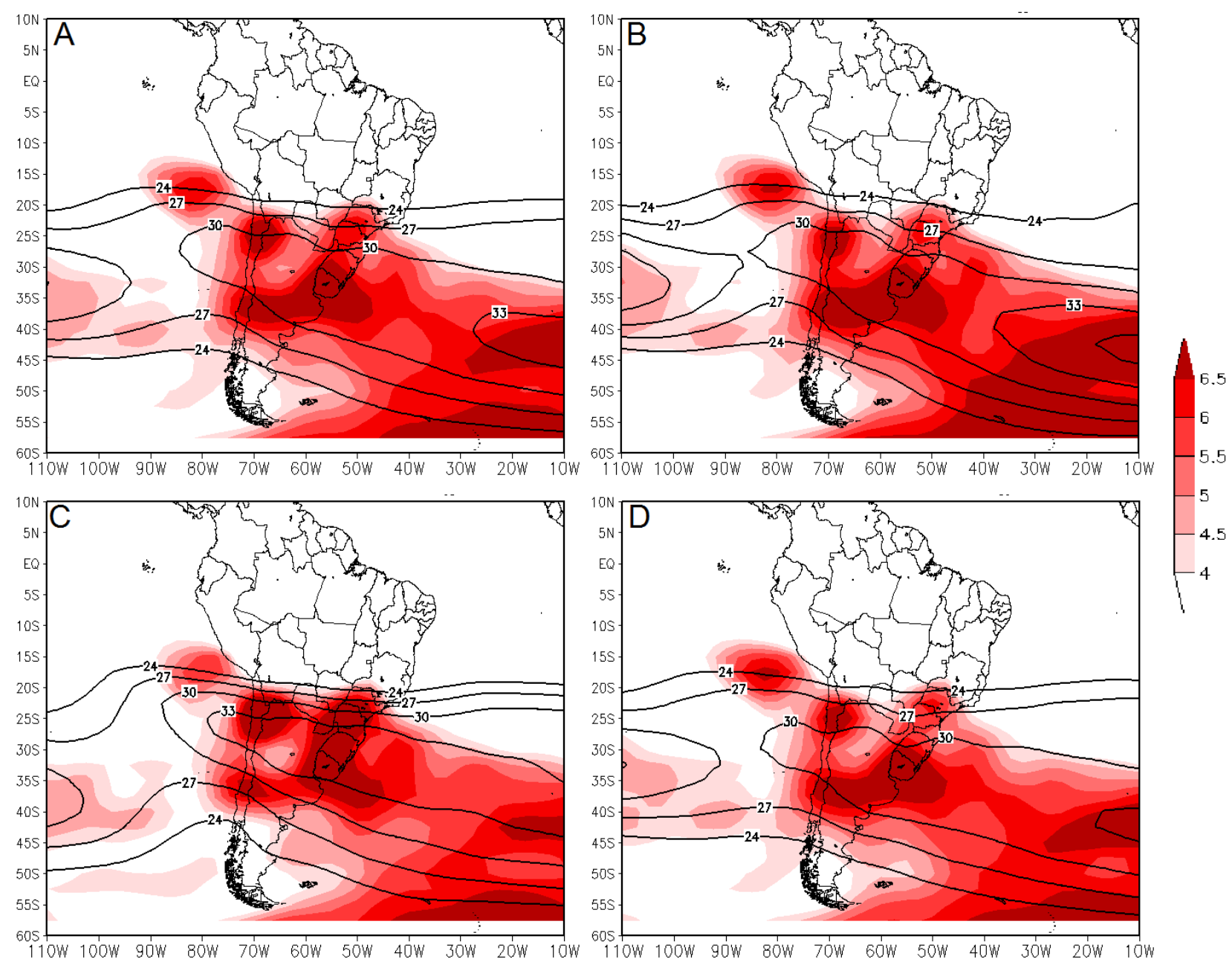

Figura 5. Campo de magnitude do vento $\left(\mathrm{m} \mathrm{s}^{-1}\right)$ em $250 \mathrm{hPa}$ para valores acima de $24 \mathrm{~m} \mathrm{~s}^{-1}$ (contorno) e

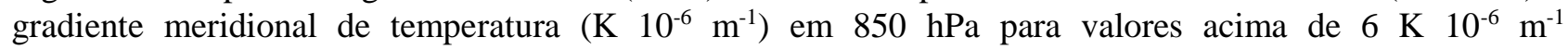
(sombreado), para o inverno (JJA) onde (A) é a média climatológica, (B) é a média dos meses com EN, (C) a média dos meses com LN e (D) a média dos meses neutros. 

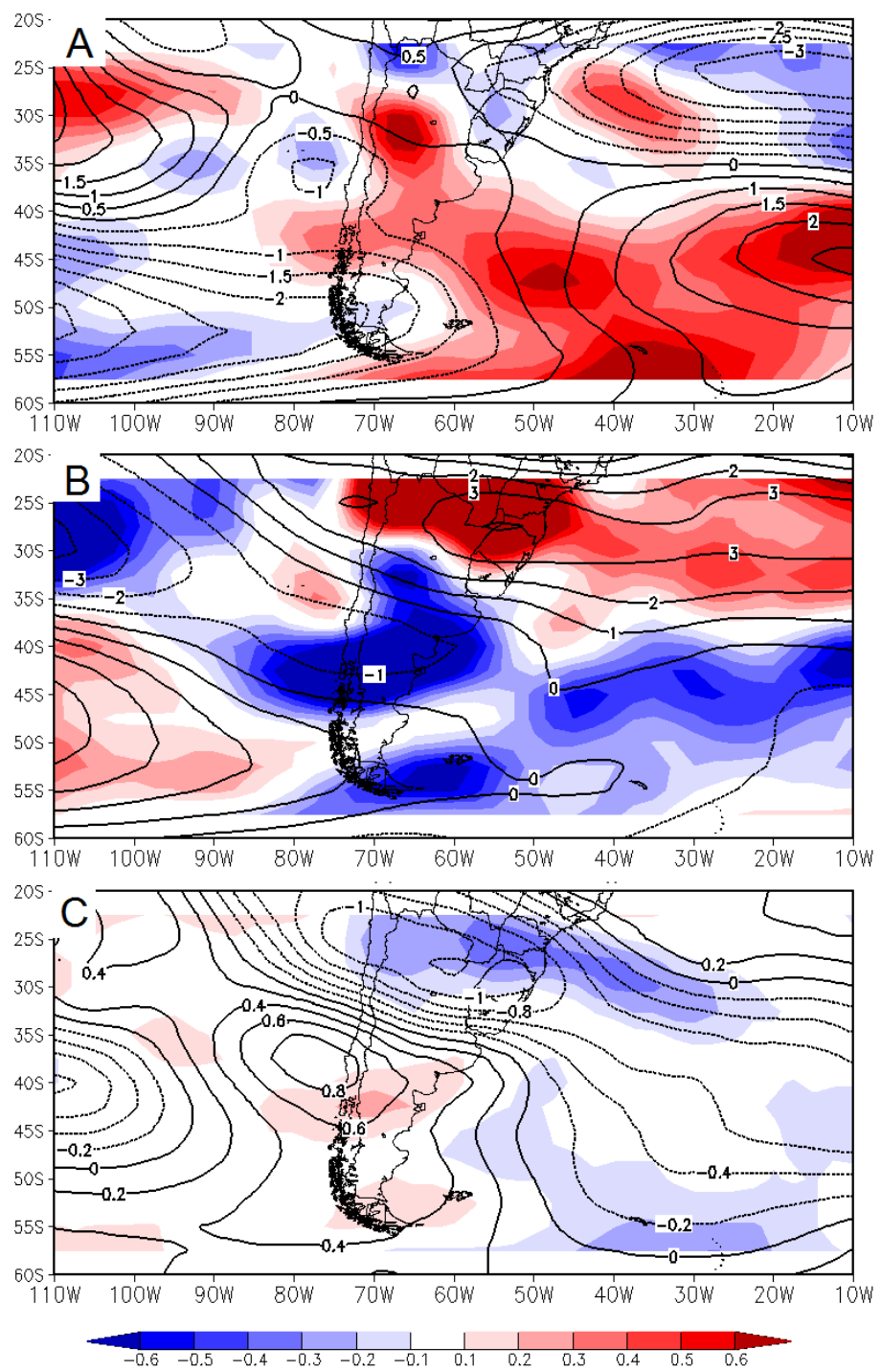

Figura 6. Anomalias (diferença entre o evento e a média climatológica) de magnitude do vento ( $\mathrm{m} \mathrm{s}^{-1}$ ) em

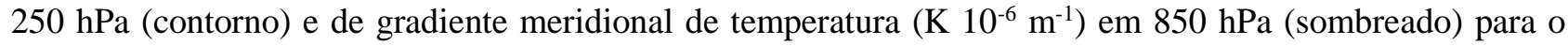
inverno (JJA) onde (A) é a média dos meses com EN, (B) é a média dos meses com LN e (C) a média dos meses neutros. 

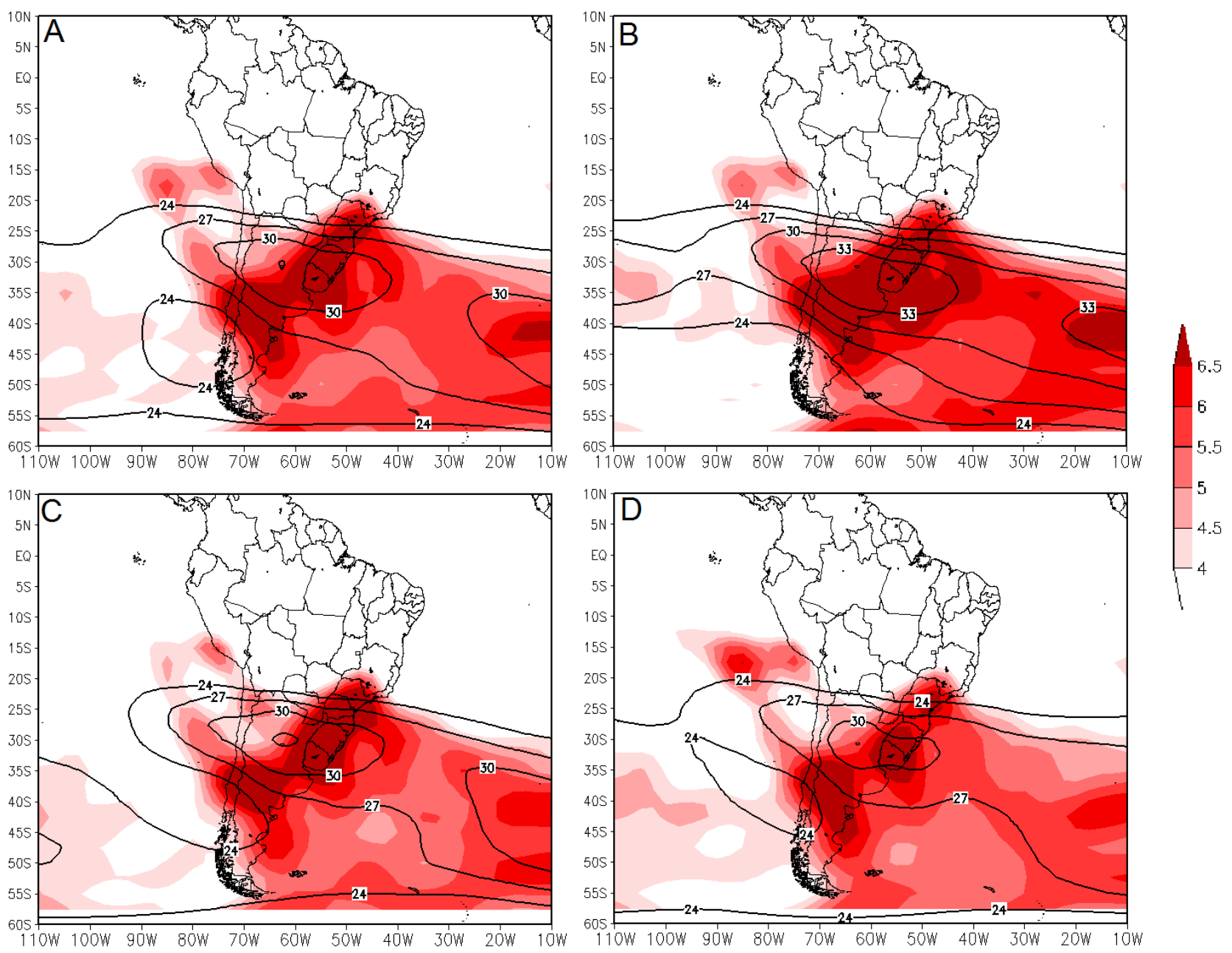

Figura 7. Campo de magnitude do vento $\left(\mathrm{m} \mathrm{s}^{-1}\right)$ em $250 \mathrm{hPa}$ para valores acima de $24 \mathrm{~m} \mathrm{~s}^{-1}$ (contorno) e gradiente meridional de temperatura $\left(\mathrm{K}_{10} 10^{-6} \mathrm{~m}^{-1}\right)$ em $850 \mathrm{hPa}$ para valores acima de $6 \mathrm{~K}^{10} 0^{-6} \mathrm{~m}^{-1}$ (sombreado), para a primavera (SON) onde (A) é a média climatológica, (B) é a média dos meses com EN, (C) a média dos meses com LN e (D) a média dos meses neutros. 

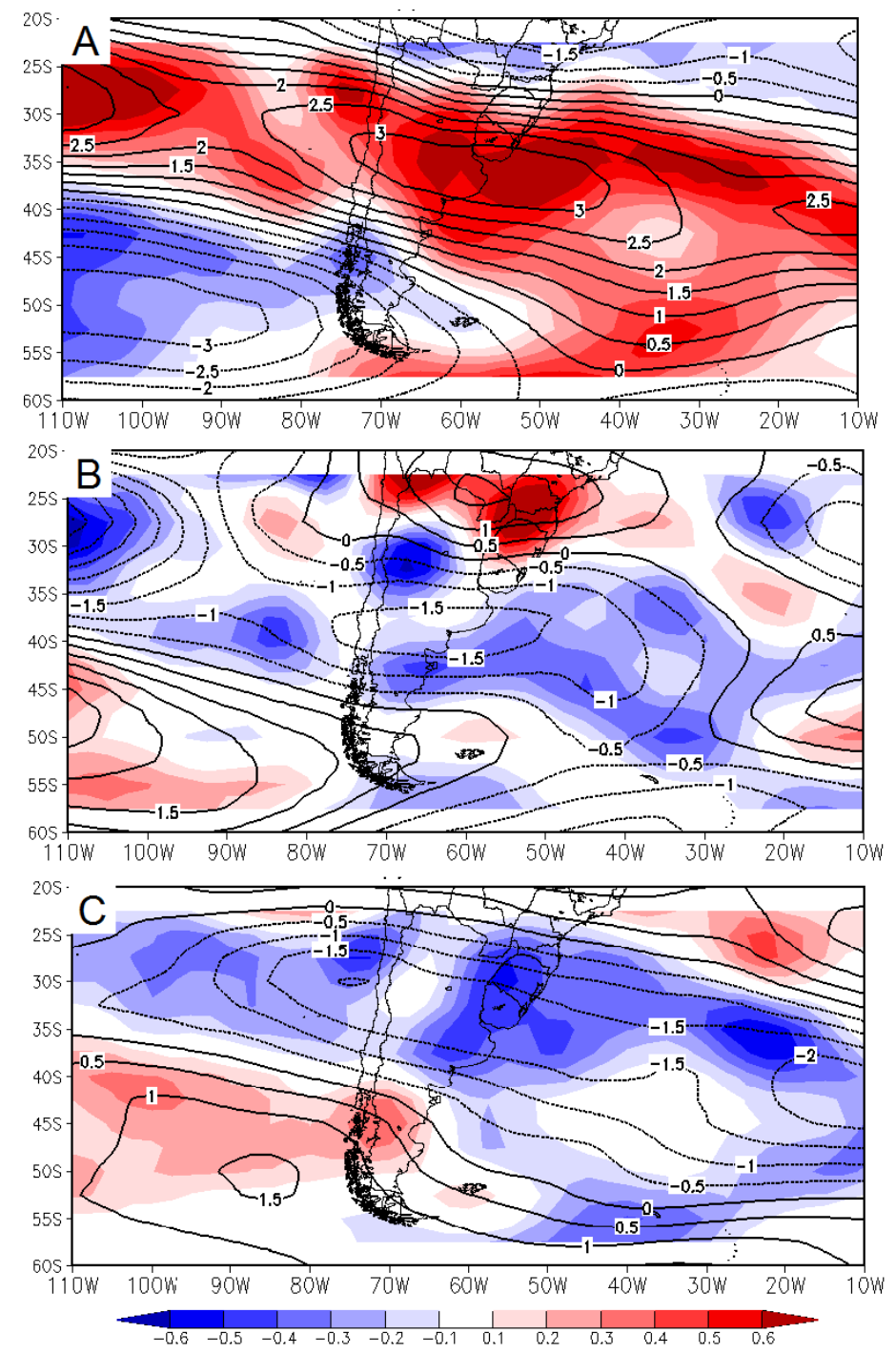

Figura 8. Anomalias (diferença entre o evento e a média climatológica) de magnitude do vento ( $\mathrm{m} \mathrm{s}^{-1}$ ) em

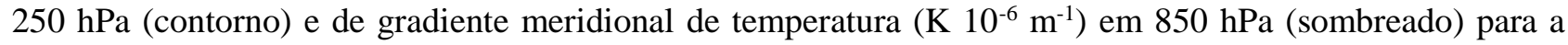
primavera (SON) onde (A) é a média dos meses com EN, (B) é a média dos meses com LN e (C) a média dos meses neutros.

As figuras 1, 3, 5 e 7 indicam, assim como as médias climatológicas, relação direta entre o jato e o gradiente de temperatura em baixos níveis para as diferentes fases do ENOS. A Tabela 2 mostra esta relação por meio do cálculo da correlação espacial, para o domínio latitudinal de $15^{\circ} \mathrm{S}$ a $60^{\circ} \mathrm{S}$, como na Tabela 1. Assim como no caso das médias, também se verificou (não mostrado aqui), para todas as fases e estações do ano, relação maior do vento em $250 \mathrm{hPa}$ com o gradiente em $850 \mathrm{hPa}$ do que com o gradiente em $1000 \mathrm{hPa}$. Assim como no caso das médias climatológicas (Tabela 1), nota-se que o inverno (JJA) é a estação em que o balanço do vento térmico é menos observado, para todas as fases do ENOS; contudo, conforme a metodologia de Yang e Delsole (2012), podemos considerar que no caso de EN a correlação é ao menos moderada nesta estação. Igualmente, de acordo com esta metodologia, podemos considerar a correlação da primavera (SON) como robusta somente para os casos de EN, e moderada nos demais. Enquanto que no outono (MAM) nas fases de EN e LN temos uma pequena diminuição da correlação em comparação com o verão (DJF), esta diminuição não é notada nos anos neutros, assim como praticamente não é notada na média climatológica.

Tabela 2. Correlação espacial média para cada estação do ano entre o gradiente meridional de temperatura em $850 \mathrm{hPa}$ ) e a magnitude do vento (valores acima de $24 \mathrm{~m} \mathrm{~s}^{-1}$ ) em $250 \mathrm{hPa}$ para as diferentes fases do ENOS.

\begin{tabular}{ccccc}
\hline & DJF & MAM & JJA & SON \\
\hline El Niño & 0.88 & 0.79 & 0.52 & 0.78 \\
\hline $\begin{array}{c}\text { La } \\
\text { Niña }\end{array}$ & 0.88 & 0.79 & 0.48 & 0.73 \\
\hline Neutro & 0.89 & 0.89 & 0.41 & 0.68 \\
\hline
\end{tabular}


Casos Especiais - as figuras acima representam valores médios dos eventos de ENOS, independente da magnitude dos mesmos. Desta forma, resta saber se eventos intensos apresentam comportamento similar. Os dados do índice ONI do CPC/NOAA indicam para o período de estudo deste trabalho (1981-2010) que os maiores valores trimestrais, considerando os trimestres DJF, MAM, JJA e SON, para EN foram em DJF de 1982/1983 (2.1) e em SON de 1997 (2.2), enquanto que para LN foram em DJF de 1988/1989 (-1.6) e em DJF de 1999/2000 (-1.6).

Observou-se, para os eventos especiais de EN, razoável associação entre gradiente de temperatura em $850 \mathrm{hPa}$ e a corrente de jato. $\mathrm{O}$ cálculo da correlação linear indica 0.85 (correlação robusta) para o caso de DJF de 1982/1983 e 0.65 (correlação moderada) para o caso de SON em 1997. Já para os dois casos especiais de LN, DJF em 1988/1989 e DJF em 1999/2000, observou-se correlações robustas de
0.85 e 0.84 , respectivamente. Comparando com a Tabela 2, nota-se que os casos especiais apresentam uma associação ligeiramente menor com relação à média dos eventos.

Especialmente sobre o continente, observou-se que o caso de EN de DJF de 1982/83 (Figura 9) apresentou um comportamento similar à média dos casos de EN para o verão (Figura 2), porém com maior intensidade das variáveis. $\mathrm{O}$ mesmo pode-se dizer do caso de SON de 1997 (Figura 9) ao comparar com a média da estação (Figura 8). Já nos casos de LN (Figura 10), ambos para DJF, observa-se certa diferença para a média da estação (Figura 2) com relação às zonas de gradiente de temperatura, principalmente quanto ao caso de 1988/89 (Figura 10A). Ou seja, estes quatro exemplos mostraram que, no geral, quanto maior a intensidade do ENOS maior a intensidade do gradiente de temperatura e do jato, o que explica a maior intensidade das consequências do fenômeno climático, conforme indica, por exemplo, Cai et al. (2003).

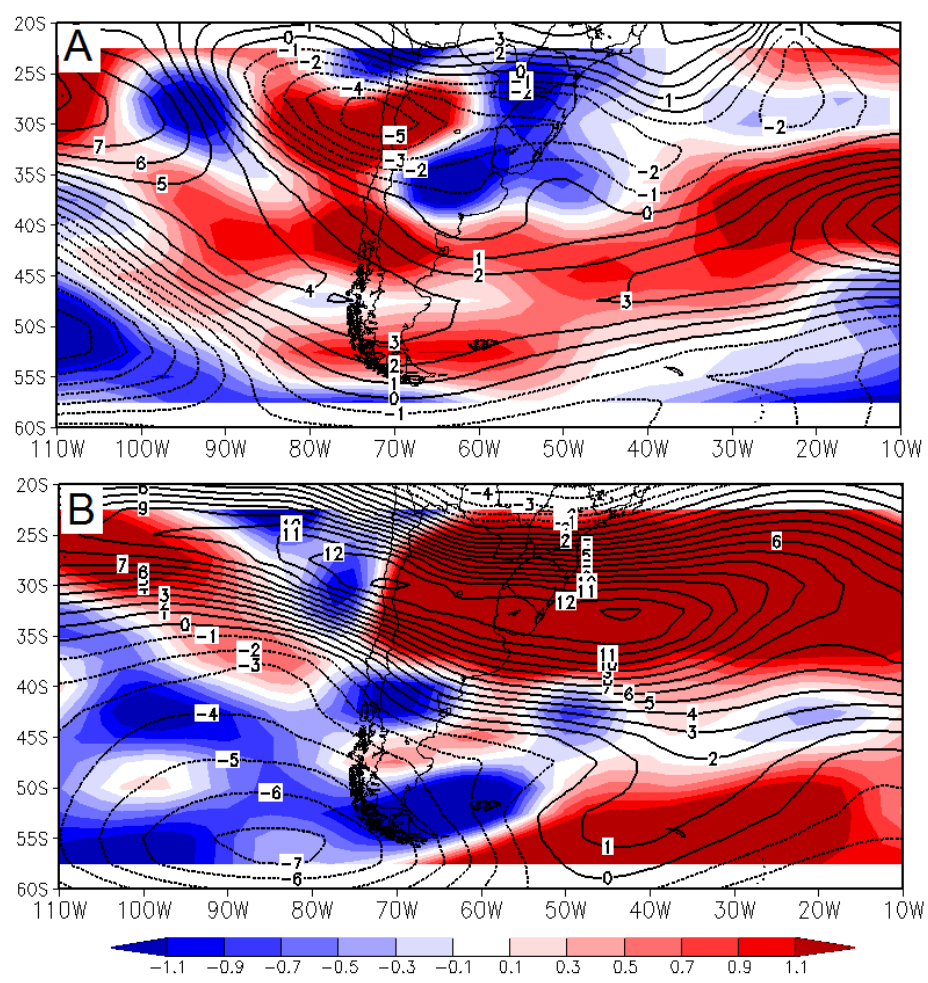

Figura 9. Anomalias (diferença entre o evento e a média climatológica) de magnitude do vento ( $\mathrm{m} \mathrm{s}^{-1}$ ) em

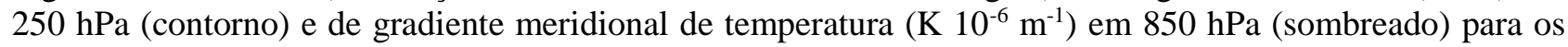
casos de EN de DJF de 1982/83 (A) e SON de 1997 (B). 


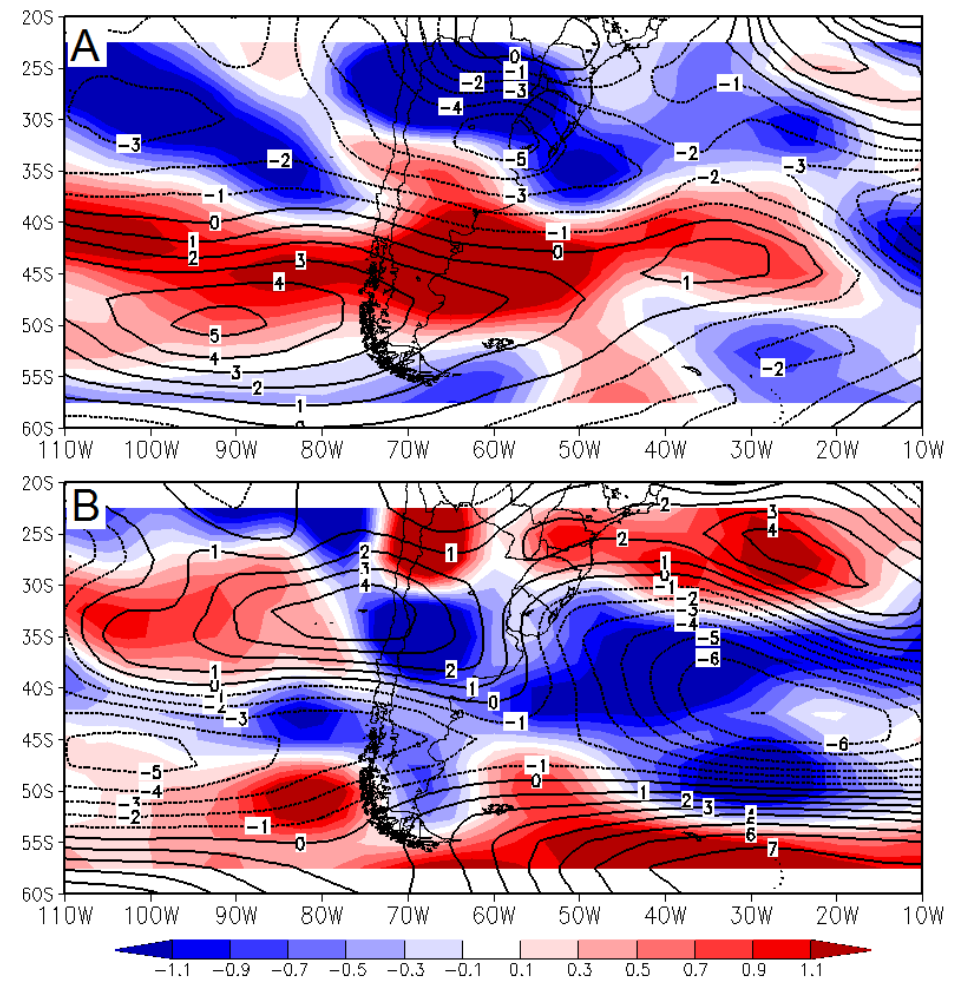

Figura 10. Anomalias (diferença entre o evento e a média climatológica) de magnitude do vento $\left(\mathrm{m} \mathrm{s}^{-1}\right)$ em

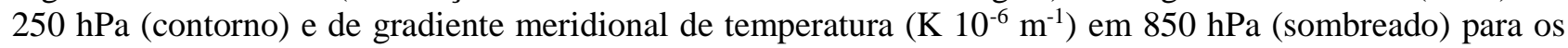
casos de LN para DJF de 1988/89 (A) e para DJF de 1999/2000 (B).

\section{Conclusões}

A análise sazonal média sobre a América do Sul da relação entre o gradiente meridional de temperatura em baixos níveis $(850 \mathrm{hPa})$ e a corrente de jato é apresentada neste trabalho por meio de dados de reanálise II do NCEP, considerando as diferentes fases do fenômeno ENOS. Por serem campos médios, os resultados obtidos neste trabalho não conseguem identificar os sistemas de bloqueio que explicam boa parte da precipitação acima da média no sul do Brasil em anos de El Niño. Entretanto, a média sazonal do balanço do vento térmico indica, no geral, uma maior chance de instabilidades baroclínicas em anos de EN sobre a região. Obviamente, análises mais locais exigem maior atenção, dado a heterogeneidade espacial representada nos resultados acima. Por exemplo, sobre a região da Argentina próxima a Bacia do Plata observa-se em anos de EN, a estação do outono com forte anomalia negativa de jato e de gradiente de temperatura, fato que não é observado nas outras estações sob influência do ENOS. Por outro lado, especialmente no verão e primavera, observa-se jato e gradiente de temperatura mais intensos em anos de EN nos subtrópicos $\left(30^{\circ}-40^{\circ} \mathrm{S}\right)$, indicando maior atividade baroclínica, o que justifica as anomalias de precipitação no sul do Brasil e arredores identificadas pela literatura especializada (Grimm et al., 1998, Chechi e Sanches, 2013, por exemplo).

Nota-se também os consideráveis valores de anomalia nos anos neutros. Esta diferença para a média climatológica se deve ao fato de que os anos neutros compreendem somente pouco mais da metade do período de 1981-2010. As figuras 1, 3, 5 e 7 mostram que as diferentes fases do ENOS não mudam o padrão sazonal climatológico da posição do jato: mais ao sul no verão e outono, e mais ao norte no inverno e primavera. Analisando os núcleos do jato, considerados aqui como os centros com valores médios acima de $30 \mathrm{~m} \mathrm{~s}^{-1}$, nota-se que em anos de EN o jato se encontra mais intenso na primavera, e em anos de $\mathrm{LN}$, no inverno. Tais núcleos intensos estão relacionados com centros intensos de gradiente de temperatura. Assim como na média climatológica, nas diferentes fases do ENOS o balanço do vento térmico pode ser observado pela correlação espacial entre a magnitude do vento em $250 \mathrm{hPa}$ e o gradiente meridional de temperatura em $850 \mathrm{hPa}$ em todas as estações, mas com valores bem menores no inverno. 
$\mathrm{Na}$ análise de casos especiais de EN e LN intensos, observa-se que os mesmos estão associados a valores mais intensos tanto de gradiente de temperatura quando de velocidade do vento do jato, o que tende a implicar em consequências mais intensas quanto à precipitação (Cai et al., 2003).

Finalmente, estes resultados preliminares mostram que o aquecimento da superfície do mar do Pacífico tropical leste (Niño 3.4), especialmente no verão e primavera, acarreta em um maior gradiente meridional de temperatura em baixos níveis, levando a um aumento da intensidade da corrente de jato sobre a região (costa oeste) da América do Sul. Ou seja, o EN intensifica o balanço do vento térmico no Pacífico leste. Trabalhos futuros deverão relacionar $\mathrm{o}$ balanço do vento térmico com os sistemas de precipitação característicos a cada fase do ENOS.

\section{Agradecimentos}

Os autores agradecem ao Msc. Mateus Dias Nunes pelas dicas úteis do software CDO (Climate Data Operators).

\section{Referências}

Ashok, K.; Behera, S.K.; Rao, S.A.; Weng, H.; Yamagata, T. 2007. El Niño Modoki and its possible teleconection. Journal of Geophysical Research 112, C11007. DOI: 10.1029/2006JC003798.

Barros, V.R.; Grimm, A.M.; Doyle, M.E. 2002. Relationship between temperature and circulation in Southern South America and its influence from El Niño and La Niña events. Journal of Meteorological Society of Japan $80,33-44$.

Bluestein, H.B., 1992. Synoptic-dynamic meteorology in midlatitudes. Volume I: Principles of kinematics and dynamics. Oxford University Press, New York.

Bluestein, H.B.; Speheger, D.A. 1995. The dynamics of an upper-level trough in the baroclinic westerlies: Analysis based upon data from a wind profiler network. Monthly Weather Review 123, 2369-2383.

Cai, W.; Collier, M.A.; Gordon, H.B.; Waterman, L.J. 2003. Strong ENSO variability and a Super-ENSO pair in the CSIRO Mark 3 coupled climate model. Monthly Weather Review 131, 1189-1210.

Chechi, L.; Sanches, F.O. 2013. O uso do Índice de Anomalia de Chuva (IAC) na avaliação do fenômeno El Niño Oscilação Sul (ENOS) no Alto Uruguai Gaúcho entre 1957-2012.
Revista Brasileira de Geografia Física 6, 1586-1597.

Coelho, C.A.S.; Uvo, C.B.; Ambrizzi, T. 2002. Exploring the impacts of the tropical Pacific SST on the precipitation patterns over South America during ENSO periods. Theoretical and Applied Climatology 71, 185-197.

Freire, J.L.M.; Lima, J.R.A.; Cavalcanti, E.P. 2011. Análise de aspectos meteorológicos sobre o Nordeste do Brasil em anos de El Niño e La Niña. Revista Brasileira de Geografia Física 4, 429-444.

Fuenzalida, H. A.; Sanchez, R.; Garreaud, R.D. 2005. A climatology of cutoff lows in the Southern Hemisphere. Journal of Geophysical Research 110, D18101. doi:10.129/2005JD005934.

Gan, M.A.; Rao, V.B. 1991. Surface cyclogenesis over South America. Monthly Weather Review 119, 1293-1302.

Garreaud, R.D.; Fuenzalida, H.A. 2007. The influence of the Andes on cutoff lows: a modeling study. Monthly Weather Review 135,1596-1613.

Grimm, A.M.; Ferraz, S.E.T.; Gomes, J. 1998. Precipitation anomalies in Southern Brazil associated with El Niño and La Niña events. Journal of Climate 11, 2863-2880.

Grimm, A.M.; Barros, V.R.; Doyle, M.E. 2000. Climate variability in Southern South America associated with $\mathrm{El}$ Niño and $\mathrm{La}$ Niña events. Journal of Climate 13, 35-58.

Grimm, A.M. 2003. The El Niño impact on the summer monsoon in Brazil: regional processes versus remote influences. Journal of Climate 16, 263-280.

Grimm, A.M. 2004. How do La Niña events disturb the summer monsoon system in Brazil? Climate Dynamics 22, 123-138.

Grimm, A.M.; Tedeschi, R.G. 2009. ENSO and extreme rainfall events in South America. Journal of Climate 22, 1589-1609. DOI: 10.1175/2008JCLI2429.1

Grimm, A.M.; Aceituno, P. 2015. El Niño, novamente! Revista Brasileira de Meteorologia 30, 351-357.

Holton, J. R., 2004. An Introduction to Dynamic Meteorology, 4 ed. San Diego, Elsevier.

Kanamitsu, M.; Ebisuzaki, W.; Woollen, J.; Yang, S-K; Hnilo, J.J.; Fiorino, M.; Potter, G. L. 2002. NCEP-DOE AMIP-II Reanalysis (R2). Bulletin of the American Meteorological Society 11, 1631-1643.

Keyser, D.; Shapiro, M.A. 1986. A review of the structure and dynamics of upper-level frontal zones. Monthly Weather Review 114, 452499. 
Marengo, J.A. 1992. Interannual variability of surface climate in the Amazon basin. International Journal of Climatology 12, 853863.

Nunes, A.B. Estudo de caso de sistemas meteorológicos em altos níveis sobre a América do Sul: Análise Sinótica. 2017. Anuário do Instituto de Geociências - UFRJ 40, 70-82. DOI: 10.11137/2017_1_70_82

Palmén, E.; Nagler, K.M. 1949. The formation and structure of a large-scale disturbance in the westerlies. Journal of Meteorology 6, 228-242.

Pereira, H.P.; Reboita, M.S.; Ambrizzi, T. 2017. Características da Atmosfera na Primavera Austral Durante o El Niño de 2015/2016. Revista Brasileira de Meteorologia 32, 293310.

Rao, V.B.; Hada, K. 1990. Characteristics of rainfall over Brazil: annual variations and connections with the Southern Oscillation. Theoretical and Applied Climatology 42, 8190.

Reboita, M.S.; Da Rocha, R. P.; Ambrizzi, T.; Sugahara, S. 2010. South Atlantic ocean cyclogenesis climatology simulated by regional climate model (RegCM3). Climate Dynamics 35, 1331-1347.

Rodrigues, L.A.; Souza, W.M.; Costa, V.S.O.; Pereira, M.L.T. 2017. Influência dos eventos El Niño e La Niña no regime de precipitação do Agreste de Pernambuco. Revista Brasileira de Geografia Física 10, 1995-2010.

Rutllant, J.; Fuenzalida, H. 1991. Synoptic aspects of the central Chile rainfall variability associated with the Southern Oscillation. International Journal of Climatology 11, 6376.
Salazar-Gáscon, R.E.; Ferreira, C.C.M. 2018. Influência do ENOS e AMO entre 2003-2014 no clima e regimes de fogo na Gran Sabana, Parque Nacional Canaima, Guiana Venezuelana. Revista Brasileira de Climatologia 22, 55-75.

Santos, D.C.; Medeiros, R.M.; Brito, J.I.B. 2013. Análise de índices de precipitação na Amazônia Ocidental. Revista Brasileira de Geografia Física 6, 1336-1355.

Satyamurty, P.; Nobre, C.A.; Silva Dias, P.L. 1998. Meteorology of the Tropics: South America, in: Karoly, D. J.; Vincent, D. G. (eds.). Meteorology of the Southern Hemisphere. Meteorological Monographs 27, 49, chapter $3 \mathrm{~A}$.

Seluchi, M.E.; Saulo, A.C.; Nicolini, M.; Satyamurty, P. 2003. The Northwestern Argentinean Low: A study of two typical events. Monthly Weather Review 131, 23612378.

Sousa, A.M.L.; Rocha, E.J.P.; Vitorino, M.I.; Souza, P.J.O.P.; Botelho, M.N. 2015. Variabilidade espaço-temporal da precipitação na Amazônia durante eventos ENOS. Revista Brasileira de Geografia Física 8, 13-24.

Tedeschi, R.G.; Cavalcanti, I.F.A.; Grimm, A.M. 2013. Influences of two types of ENSO on South American precipitation. International Journal of Climatology 33, 1382-1400.

Velasco, I., Fritsch, J.M. 1987. Mesoscale convective complex in the Americas. Journal of Geophysical Research 92, 9591-9613.

Yang, X.; DelSole, T. 2012. Systematic comparison of ENSO teleconnection patterns between models and observations. Journal of Climate 25, 425-446. 